\section{Method of Trial}

Twenty patients ( 2 women and 18 men) took part in the trial. Their mean age was 59.5 years (range 46-70 years). All had typical severe angina due to coronary artery disease, constant in degree for at least two months before the trial. Aortic stenosis was also present in two patients, rheumatic aortic incompetence in one, and mitral stenosis in one. The electrocardiogram was abnormal in 16 patients, with evidence of infarction in eight and of ischaemia in the remaining eight. Eleven patients were previously receiving anticoagulants and continued them throughout the trial.

A double-blind cross-over technique was used, each patient acting as his own control. The 20 patients were allocated to two equal groups by a random method. One group took tersavid for a month followed by identical inert tablets for a second month, and the other group took inert tablets followed by tersavid. No other alteration of treatment was made during the period of the trial. At the start of the tersavid period treatment was begun with $150 \mathrm{mg}$. daily. If there was no improvement in angina after one week, the dose was increased to $250 \mathrm{mg}$. daily and continued at this level for the next three weeks. The dose of inert tablets was similarly increased if angina continued unchanged after one week of the control period. The patients were seen at fortnightly intervals throughout the trial, when the severity of angina and the number of trinitrin tablets required were recorded. Weight, blood-pressure, evidence of fluid retention, and side-effects were also noted. An electrocardiogram was taken and serum glutamicoxaloacetic and glutamic-pyruvic transaminase levels were estimated at monthly intervals.

\section{Results}

One patient, a man on anticoagulant treatment, died of recurrent myocardial infarction after three days on control tablets. Of the remaining 19 patients, only the one man with aortic incompetence reported improvement in angina with tersavid and no benefit from the inert tablets. Seven patients improved during both trial periods, and in the remaining 11 patients there was no significant change in angina. Three patients had associated intermittent claudication. In one of these-the one patient who reported benefit from tersavid-leg pain also decreased. The other two patients found no change in angina or leg pain.

No side-effects occurred apart from slight dizziness in two patients. There was no change in weight or bloodpressure, and no evidence of fluid retention. The electrocardiograms were also unchanged, and the transaminase levels remained normal.

\section{Discussion}

There is real need for a drug capable of producing prolonged relief of angina. The most widely prescribed remedy, pentaerythritol tetranitrate (P.E.T.N.), we have recently tried in high dosage on a double-blind basis with negative results. Twelve patients with angina received $60 \mathrm{mg}$. of P.E.T.N. three times daily for a month and identical inert tablets for another month. None found improvement on P.E.T.N. and not on control tablets. Similar negative results were reported by Dewar et al. (1959).

Recent experience with iproniazid is disappointing, and it may be doubted whether other monoamine oxidase inhibitors will relieve angina if iproniazid does not. The present trial, in which only 1 out of 19 patients improved while on tersavid and not during the control period, does not indicate that this drug is valuable in angina. However, in a recent trial of $\beta$-phenylisopropylhydrazine ("cavodil ") (MacKinnon et al., 1960) our experience has been less encouraging. Hepatic damage, with jaundice, developed in one of the 12 patients treated with it.

\section{Summary}

A monoamine oxidase inhibitor, tersavid, has been tried on a double-blind basis in 19 patients with angina. Only one patient appeared to benefit.

We are grateful to Dr. Horace Joules and Dr. Keith Ball for help with this trial. The tersavid and control tablets were kindly supplied by Roche Products Ltd.

\section{REFERENCES}

Cesarman, T. (1957). Arch. Inst. Cardiol. Méx., 27, 563.

Cossio, P. (1958). Amer. Heart J., 56, 113.

Dewar, H. A., Horler, A. R., and Newell, D. J. (1959). Brit. Heart J., 21, 315.

Fife, R., Howitt, G., and Stevenson, J. (1960). Brit. med. J., 1 , 692.

Mackinnon, J., Anderson, D. E., and Howitt, G. (1960). Ibid. $1,243$.

New Engl. J. Med., 1958, 258, 1225.

Snow, P. J. D., and Anderson, D. E. (1959). Brit. Heart J., 21, 323.

Towers, M. K., and Wood, P. (1958). Brit. med. J., 2, 1067.

\section{Medical Memoranda}

\section{Megimated Barbiturates}

Partly owing to the wider prescription of barbiturates the mortality and morbidity from overdosage, accidental or suicidal, has risen considerably over the last decade. We are faced with a serious problem: 2,800 hospital cases of barbiturate poisoning were treated in 1949 and 6,000 in 1958 . We can, with reasonable certainty, expect an even greater rise over the years ahead. There are two alternatives to combat this rise: either to stop using barbiturates or to safeguard their use. Some measures have, of course, already been taken to control their prescription and use. However, something more is needed, since the number of deaths continues to rise despite these statutory measures.

Attempts have been made to make barbiturates less dangerous by combining them with emetics and stimulants. These combinations appear to have had little success in practice. Following the work on bemegride (" megimide ") by Shaw and his co-workers in 1954, over 200 articles appeared on its use in the treatment of barbiturate overdosage. These articles provided confirmation of the effectiveness of bemegride as a functional barbiturate antagonist. It seemed possible, therefore, that a combination of bemegride with barbiturates might lower the potential toxicity of overdosage from barbiturates. Trautner et al. (1957) and Gershon and Shaw (1957) were able to show that $10-20 \%$ bemegride with barbiturate in tablet form reduced or even prevented the development of coma or of prolonged sleep in doses of up to $2.6 \mathrm{~g}$. of barbiturate. Quite naturally the critical test of whether this combination is effective in preventing death due to gross overdosage can never be performed 
deliberately. Further data on its efficiency at very high dose levels has therefore had to be awaited.

First indications promised vindication of the belief upon which the "megimated barbiturates" were founded. Thus Skinner (1960) reported a case in which 50 "phenaglate" capsules (quinalbarbitone sodium $50 \mathrm{mg}$., phenobarbitone $25 \mathrm{mg}$., bemegride $7.5 \mathrm{mg}$.) had been taken with no resultant coma or respiratory depression. Heffernan (1959) reported a case in which 24 capsules were taken without any ill effect. Two similar cases have been reported to one of us personally in which " mylomide" (amylobarbitone $100 \mathrm{mg}$., bemegride $10 \mathrm{mg}$.) was taken in overdosage. In one case 25 tablets were taken, the stimulant effect of the bemegride being prominent, since after a number of hours of light sleep the patient awoke feeling excited. In the second case at least 16 tablets were taken; the patient was in light coma, but there was no respiratory depression.

Despite these earlier encouraging reports, a note of caution must now be introduced because of the occurrence of a death caused by the ingestion of a large amount of phenaglate.

\section{CASE REPoRT}

The patient was a man aged 39. He was single, a clerk by profession, although he had been away from work for two weeks previous to his first admission to hospital, which was on April 9, 1957.

He had enjoyed fairly good health before and there was no history of psychiatric disorder in his family. The condition leading to his admission began towards the end of March, 1957, when he felt anxious and worried about an unhappy love affair. His anxiety became more acute, until on April 8, he attempted suicide by coal gas.

In hospital he was found to be acutely anxious and tense though he was not overtly depressed. To overcome the anxiety and tension he was sedated with amylobarbitone sodium, 1 gr. $(65 \mathrm{mg}$.) t.d.s. No other treatment was given. On this regime he improved gradually, and was apparently well enough for discharge on May 25. Five days later he again attempted suicide with coal gas. He was readmitted to hospital, and, because he was thought to be depressed, was treated with E.C.T. and chlorpromazine. He received a total of 5 E.C.T.s and $75 \mathrm{mg}$. of chlorpromazine t.d.s. He responded well and left hospital on August 10.

After leaving hospital he returned to his work for about two months. He then refused to go to work or to attend the hospital. However, on September 8, 1959, he made a third attempt on his life with coal gas. This was brought about by acute worry, the patient fearing that his girl friend was pregnant by him. On readmission he was again anxious and tense, but not depressed. He was treated by sedation with phenaglate, two capsules of this preparation being given three times a day. With this treatment his condition improved until he was discharged from in-patient care on October 20. He was seen regularly as an out-patient until March 12,1960, when he claimed that he had weaned himself off the capsules and that he felt there was no further need to attend the hospital. Objectively he was well and was quite free from symptoms.

Six weeks later, without warning he committed suicide, using about 120 hoarded phenaglate capsules for the purpose.

Post-mortem Findings.-Necropsy revealed no anatomical abnormality to account for the patient's death. Chemical analysis of the body organs and contents was carried out at the Area Home Office Forensic Science Laboratories. The following total amounts of barbiturate were discovered:

\begin{tabular}{|c|c|c|c|}
\hline Stomach & contents & & 2.7 g. (approximately 40 gr.) \\
\hline Blood . & 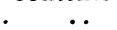 & & mg./100 g. \\
\hline Liver & .. & .. & $7.5 \mathrm{mg} . / 100 \mathrm{~g}$. \\
\hline Brain .. & . & . & $4.1 \mathrm{mg} . / 100 \mathrm{~g}$ \\
\hline Kidney & $\ldots$ & $\ldots$ & $4.6 \mathrm{mg} . / 1$ \\
\hline
\end{tabular}

Analysis of the blood and liver revealed the presence of approximately equal quantities of phenobarbitone and quinalbarbitone in those tissues. Apart from the stomach contents, bemegride was found in the highest concentration in the brain. In the latter organ there was $0.7 \mathrm{mg} / 100 \mathrm{~g}$. bemegride present.

These findings, together with the clinical evidence, were taken to indicate that the cause of death was barbiturate poisoning from an overdose of phenaglate capsules.

\section{COMMENT}

In view of the rapidly rising toll of deaths from barbiturate poisoning it is reasonable to attempt new steps to limit the dangerous potentialities of these widely used drugs. The best solution of all would be, of course, to stop using barbiturates altogether. Unfortunately there is as yet no alternative available that combines all the essential therapeutic properties of the barbiturates with a complete absence of toxicity. Statutory control of the prescription and issue of barbiturates has the effect of limiting addiction and the indiscriminate use of these dangerous drugs. But there still remains great danger to those who require large amounts of barbiturates for their effective management. There is the problem of the suicidal patient who hoards his drugs for an attempt on his own life, and also the problem of overdosage by accident.

The megimated barbiturates are based on the known properties of bemegride and its antagonism to barbiturates. They were introduced in an attempt to reduce the toll of deaths from barbiturate poisoning after clinical and other work by Professor Shaw and his colleagues in Australia on various combinations of bemegride with the barbiturates.

It is clearly too early to express dogmatic opinions on the relative "safety" of the megimated and "plain" barbiturates. The most one can say is that there is promise that the megimated barbiturates have less lethal potentiality than unmodified barbiturates but that there is probably a limit beyond which megimation cannot prevent the onset of coma which may be deep enough to cause death. Up to a certain hypothetical ceiling overdosage appears to be attended by less risk with the megimated barbiturates. However, the occurrence of one case in which death occurred after approximately one hundred capsules of phenaglate were swallowed must indicate that the advantages of megimated barbiturates have limits. How far these limits extend to provide a useful advantage over unmodified barbiturates must be related to the individual practice of the doctor prescribing them, the patient under treatment, and several other circumstances governing the effects of these sedative-hypnotic drugs.

We are indebted to Dr. T. M. Cuthbert, the physiciansuperintendent, St. Luke's Hospital, for his permission to publish this, and to Dr. A. S. Curry, of the Forensic Science Laboratories, North Eastern Area, for supplying us with the data relating to the post-mortem findings.

\section{B. W. McGuinNESS, M.D.,}

Aspro-Nicholas Limited, Slough.

F. J. RoberTS, M.B., B.S., M.R.C.S., L.R.C.P.,

Registrar in Psychiatry, St. Luke's Hospital, Middlesbrough.

\section{REFERENCES}

Gershon, S., and Shaw, F. H. (1957). Brit. med. J., 2, 1509.

Heffernan, D T. (1959). Ibid., 2, 1097.

Skinner, J. K. (1960). Ibid., 1, 1058.

Trautner, E. M., Murray, T. W., and Noack, C. H. (1957). Ibid., 2. 1514 . 